\title{
In vitro and in vivo antitumor effects of recombinant bispecific antibodies based on humanized anti-EGFR antibody
}

\author{
YASUHIRO WATANABE ${ }^{1}$, RYUTARO ASANO $^{2}$, KYOKO ARAI $^{2}$, IPPEI SHIMOMURA ${ }^{2}$, HIROMI OGATA ${ }^{2}$, \\ HIROKO KAWAGUCHI $^{2}$, HIROKI HAYASHI ${ }^{1}$, HIDEO OHTSUKA ${ }^{1}$, HIROSHI YOSHIDA ${ }^{1}$, YU KATAYOSE ${ }^{1}$, \\ SHINICHI EGAWA ${ }^{1}$, TAKESHI NAKANISHI ${ }^{2}$, MITSUO UMETSU ${ }^{2}$, HIROSHI YASUI ${ }^{3}$, TADAO ISHIDA ${ }^{3}$, \\ $\mathrm{KOHZOH} \mathrm{IMAI}^{3}$, TOSHIO KUDO ${ }^{4}$, MICHIAKI UNNO $^{1}$ and IZUMI KUMAGAI ${ }^{2}$ \\ ${ }^{1}$ Division of Gastroenterological Surgery, Department of Surgery, Graduate School of Medicine, \\ Tohoku University, Sendai 980-8574; ${ }^{2}$ Department of Biomolecular Engineering, Graduate School of \\ Engineering, Tohoku University, Sendai 980-8579; ${ }^{3}$ First Department of Internal Medicine, Sapporo \\ Medical University School of Medicine, Sapporo 060-8543; ${ }^{4}$ Cell Resource Center for Biomedical \\ Research, Institute of Development, Aging and Cancer, Tohoku University, Sendai 980-8575, Japan
}

Received March 12, 2011; Accepted May 9, 2011

DOI: 10.3892/or.2011.1382

\begin{abstract}
We performed in vitro and in vivo experiments of the anti-epidermal growth factor receptor (EGFR) $x$ anti-CD3 bispecific diabody (hEx3-Db) with the IgG-like bispecific antibodies (BsAbs) (hEx3-scFv-Fc and hEx3-scDb-Fc) and the anti-EGFR therapeutic antibody cetuximab to assess the effect of BsAbs on cancer growth inhibition. In vitro, efficacy of the BsAbs and cetuximab were compared by growth inhibition assays of human cell lines of bile duct (TFK-1, HuCC-T1, OCUCh-LM1), epidermoid (A431), gastric (Kato-III), colon (DLD-1, SW480), and breast (SK-BR-3, MCF-7) cancer. In vivo, in three mouse models, we evaluated the anti-tumor activity of hEx3-Db and cetuximab, assessed the effect of hEx3-Db alone, and compared the antitumor activity of hEx3-Db with the IgG-like BsAbs. In vitro, hEx3scFv-Fc showed nearly $100 \%$ killing activity for all cell lines. Both in vitro and in vivo, hEx3-Db needed CD3-positive phenotypes to induce a growth inhibitory effect. In contrast, IgG-like BsAbs showed monotherapeutic effects in vivo by inducing antibody-dependent cellular cytotoxicity (ADCC) similar to cetuximab. However, enhancement was not observed when lymphokine-activated killer cells with the T-cell phenotype were co-injected. Results suggest that IgG-like BsAbs could not efficiently direct $\mathrm{T}$ lymphocytes toward tumor cells to induce ADCC due to steric hindrance on binding to CD3and Fc-receptor-positive phenotypes. Although hEx3-scFv-Fc
\end{abstract}

Correspondence to: Dr Izumi Kumagai, Department of Biomolecular Engineering, Graduate School of Engineering, Tohoku University, Aoba 6-6-11-606, Aramaki, Aoba-ku, Sendai 980-8579, Japan E-mail:kmiz@kuma.che.tohoku.ac.jp

Key words: bispecific diabody, effective recombinant formats, IgG-like bispecific antibody, EGFR, cancer immunotherapy showed high cytotoxicity in vitro, its high molecular weight limits its usefulness. With an in vivo effect comparable to $\mathrm{hEx} 3-\mathrm{scFv}-\mathrm{Fc}$ and its realistic molecular weight, hEx3-scDb-Fc shows promise as a novel recombinant therapeutic antibody and may be modified to enhance its potency by prevention of steric hindrance.

\section{Introduction}

Since its identification, the epidermal growth factor receptor (EGFR) has become an attractive target molecule for cancer immunotherapy. Previous reports have demonstrated that EGFR is widely expressed in a variety of solid tumors, and its expression level is correlated with malignancy, metastatic phenotype, and poor prognosis (1-3). Two anti-EGFR therapeutic antibodies, cetuximab and panitumumab, have already been approved by the US Food and Drug Administration, and several bispecific antibodies (BsAbs) that target EGFR are in development (4-7).

BsAbs are attractive forms of recombinant antibodies that can bind to two different antigen epitopes. This bispecificity can be applied to cancer immunotherapy by cross-linking tumor cells to immune cells, such as cytotoxic T cells, natural killer cells, and macrophages. This linkage accelerates the destruction of the tumor cells by immune cells, so that compared to monospecific antibodies, the therapeutic dose can be lower $(8,9)$.

Advances in recombinant technology have made it feasible to generate small recombinant BsAbs constructed from two variable antibody fragments, such as the diabody (Db) (10), single-chain diabody ( $\mathrm{scDb}$ ) (11), and the tandem single-chain Fv (scFv) (12). In comparison to conventional BsAbs, the small recombinant BsAbs are expected to facilitate tumor penetration and homogeneous production in bacteria, and to be low in immunogenicity $(13,14)$. Previously, we determined the effectiveness in cancer immunotherapy of the $\mathrm{VH}$ and $\mathrm{VL}$ domains from the EGFR monoclonal antibody 528, and 
A

B

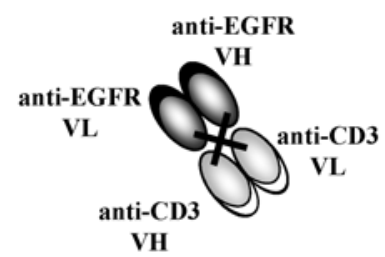

hEx3-Db

C
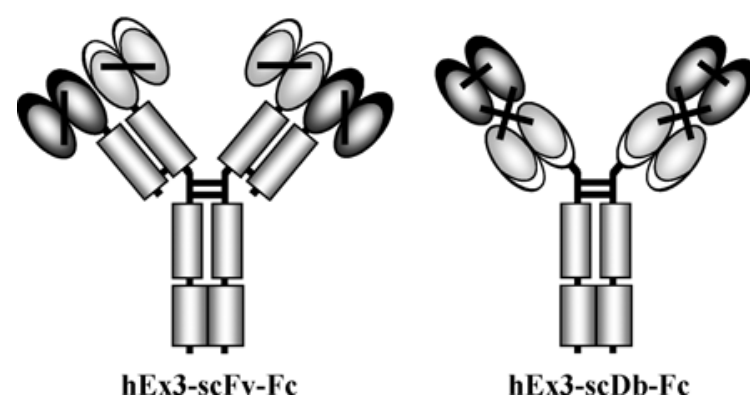

hEx3-scDb-Fc

Figure 1. Schematic diagram of hEx3-Db (A), hEx3-scDb (B), hEx3-scFv-Fc (C), hEx3-scDb-Fc (D).

constructed a humanized functional bispecific $\mathrm{Db}, \mathrm{hEx} 3-\mathrm{Db}$, that retargeted lymphokine-activated killer cells with the T-cell phenotype (T-LAK cells) against EGFR-positive cell lines $(15,16)$. Simplification of this Db has many advantages, but it also involves a decrease in valence and the removal of the Fc region. Consequently, small BsAbs are apt to show not only rapid clearance (i.e., short half-life) but also low affinity for the target and lack of induction of antibody-dependent cellular cytotoxicity (ADCC).

Recent advances in recombinant technologies have enabled the rebuilding of dissected antigen-binding regions into multivalent and more effective formats. To date, several kinds of recombinant IgG-like BsAbs with a human Fc portion have been constructed to overcome the drawbacks of small BsAbs (17-19). Evaluation of their functions has revealed that BsAbs with the $\mathrm{Fc}$ portion are attractive molecules as therapeutic reagents because they usually have several advantageous characteristics: prolonged half-life and multivalent binding to two target antigens, amenable to purification with protein $\mathrm{A}$, and ADCC induction (19-22).

Yet, there are no in vivo reports of comparative experiments with the original small recombinant formats. Therefore, we focused on IgG-like BsAbs to improve the $\mathrm{Db}$ and fabricated two IgG-like BsAbs based on hEx3-Db: hEx3-scFv-Fc and hEx3-scDb-Fc (Fig. 1) $(23,24)$. Both of these IgG-like BsAbs have two pairs of humanized $\mathrm{Fv}$ portions with specificity for EGFR and CD3, and were more cytotoxic than hEx3-Db. However, the comparison of both hEx3-scFv-Fc and hEx3$\mathrm{scDb}-\mathrm{Fc}$, with different configurations to each other, has not been conducted. Here, we performed comparative experiments between these IgG-like BsAbs with hEx3-Db and cetuximab in vitro and in vivo to explore the effect of BsAbs on cancer growth inhibition.

\section{Materials and methods}

Humanized bispecific antibodies. All Ex3 BsAbs used in this report were humanized. $\mathrm{hEx} 3-\mathrm{Db}$ was prepared from inclusion bodies expressed in Escherichia coli, as previously described $(15,25)$ and the IgG-like BsAbs, hEx3-scFv-Fc and hEx3$\mathrm{scDb}-\mathrm{Fc}$, were prepared from Chinese hamster ovary $(\mathrm{CHO})$ cells, as described in our previous study (24).

Cell lines. Human bile duct carcinoma (TFK-1, HuCC-T1, and OCUCh-LM1) (26), human epidermoid (A431), human gastric (Kato-III), human colon (DLD-1, SW480) and human breast (SK-BR-3, MCF-7) cancer cell lines were used in this study. The TFK-1 cell line was established in our laboratory (27), OCUCh-LM1 was kindly provided by Dr Yamada (Osaka City University School of Medicine, Osaka, Japan), and HuCC-T1 and Kato-III were obtained from the Japanese Cancer Research Resources Bank (Tokyo, Japan). The cell lines, A431, DLD-1, SW480, SK-BR-3, and MCF-7 were obtained from the Cell Resource Center for Biomedical Research, Institute of Development, Aging and Cancer, Tohoku University (Sendai, Japan). These cell lines were cultured in RPMI-1640 medium supplemented with $10 \%$ fetal bovine serum (FBS), $100 \mathrm{U} / \mathrm{ml}$ penicillin and $100 \mu \mathrm{g} / \mathrm{ml}$ streptomycin.

Preparation and stimulation of effector cells. For the induction of T-LAK cells, peripheral blood mononuclear cells (PBMCs) isolated by density-gradient centrifugation from a healthy volunteer were cultured for $48 \mathrm{~h}$ in a culture medium supplemented with $100 \mathrm{IU} / \mathrm{ml}$ recombinant human interleukin 2 (IL-2), kindly supplied by Shionogi \& Co., Ltd., (Osaka, Japan) at a cell density of $1 \times 10^{6} / \mathrm{ml}$ in a culture flask (Nunc A/S, Roskilde, Denmark) pre-coated with OKT3 monoclonal antibody $(10 \mu \mathrm{g} / \mathrm{ml})$. The proliferated cells were then transferred to another flask and expanded in a culture medium containing $100 \mathrm{IU} / \mathrm{ml} \mathrm{IL}-2$ for 2-3 weeks, as previously reported (28). Surface marker analysis showed $>90 \%$ of the cells were positive for CD3 and CD8, but CD56 was almost negative (29). In some cases, PBMCs isolated by density-gradient centrifugation were immediately used for in vitro growth inhibition assays.

In vitro tumor growth inhibition assay. In vitro tumor growth inhibition of the various cell lines was assayed with a 3-(4,5-dimethylthiazole-2-yl)-5-(3-carboxymethoxyphenyl)-2(4-sulfophenyl)-2H-tetrazolium inner salt (MTS) assay kit (CellTiter 96 Aqueous Non-Radioactive Cell Proliferation Assay; Promega Corporation, Madison, WI, USA). The target cells $(5,000$ cells in $100 \mu \mathrm{l}$ culture medium) were plated on 96-well, half-area (A/2), flat-bottomed plates (Costar Group, Inc., Cambridge, MA, USA). Cells were cultured overnight to allow well adhesion. After removing the culture medium by aspiration, $100 \mu 1$ of the effector cells (T-LAK cells or PBMCs) plus various concentrations of antibodies were added to each well, giving a final effector to target cell (E:T) ratio of 5,1 , or 0.2 . After culturing the cells for $48 \mathrm{~h}$ at $37^{\circ} \mathrm{C}$, each well was washed with PBS twice to remove effector cells and dead target cells, and $95 \mu \mathrm{l}$ of the culture medium plus $5 \mu \mathrm{l}$ of a fresh mixture of MTS/phenazine methosulfate solution (Promega Corporation) was added to each well. The plates 
Table I. Percentage of growth inhibition of Ab with T-LAK cells vs. T-LAK cells alone in various cancer cell lines.

\begin{tabular}{|c|c|c|c|c|c|c|}
\hline Target cells and origin & EGFR expression & T-LAK alone & Cetuximab & hEx3-Db & hEx3-scFv-Fc & hEx3-scDb-Fc \\
\hline \multicolumn{7}{|l|}{ Bile duct carcinoma } \\
\hline TFK-1 & High & $-10.1 \pm 8.7$ & $-1.6 \pm 11.7$ & $39.1 \pm 9.0^{\mathrm{d}}$ & $99.5 \pm 0.6^{\mathrm{d}}$ & $86.2 \pm 5.3^{\mathrm{d}}$ \\
\hline HuCC-T1 & High & $3.3 \pm 3.2$ & $0.9 \pm 3.6$ & $-4.9 \pm 7.7$ & $100.9 \pm 0.8^{\mathrm{d}}$ & $53.6 \pm 3.4^{\mathrm{d}}$ \\
\hline OCUCh-LM1 & High & $-3.1 \pm 10.5$ & $7.5 \pm 13.2$ & $8.0 \pm 12.4$ & $98.8 \pm 0.8^{\mathrm{d}}$ & $76.1 \pm 2.8^{\mathrm{d}}$ \\
\hline \multicolumn{7}{|l|}{ Epidermoid cancer } \\
\hline A431 & High & $5.4 \pm 8.4$ & $1.7 \pm 6.5$ & $97.0 \pm 1.4^{\mathrm{d}}$ & $98.3 \pm 0.9^{d}$ & $98.2 \pm 1.7^{\mathrm{d}}$ \\
\hline \multicolumn{7}{|l|}{ Gastric cancer } \\
\hline Kato-III & Moderate & $49.6 \pm 5.3$ & $41.7 \pm 8.4$ & $47.3 \pm 8.7$ & $100.6 \pm 0.3^{\mathrm{d}}$ & $100.6 \pm 0.3^{\mathrm{d}}$ \\
\hline \multicolumn{7}{|l|}{ Colon cancer } \\
\hline DLD-1 & Moderate & $-1.2 \pm 3.5$ & $8.4 \pm 7.0^{\mathrm{b}}$ & $57.9 \pm 5.6^{\mathrm{d}}$ & $98.6 \pm 0.8^{d}$ & $101.1 \pm 0.9^{\mathrm{d}}$ \\
\hline SW480 & Moderate & $12.8 \pm 2.1$ & $18.6 \pm 9.4$ & $39.3 \pm 5.5^{\mathrm{d}}$ & $99.7 \pm 1.4^{\mathrm{d}}$ & $99.4 \pm 0.6^{\mathrm{d}}$ \\
\hline \multicolumn{7}{|l|}{ Breast cancer } \\
\hline SK-BR-3 & Moderate & $12.1 \pm 7.6$ & $19.3 \pm 4.0^{\mathrm{a}}$ & $56.1 \pm 3.8^{\mathrm{d}}$ & $99.1 \pm 1.3^{\mathrm{d}}$ & $94.7 \pm 1.4^{\mathrm{d}}$ \\
\hline MCF-7 & Low & $-4.9 \pm 3.3$ & $8.1 \pm 2.5^{\mathrm{d}}$ & $5.1 \pm 5.3^{\mathrm{c}}$ & $99.9 \pm 1.1^{\mathrm{d}}$ & $50.9 \pm 2.6^{\mathrm{d}}$ \\
\hline
\end{tabular}

Percentage \pm standard deviation $(\mathrm{SD})$ of growth inhibition of bispecific antibodies or monospecific antibodies with T-LAK cells $(\mathrm{Ab}, 0.1 \mathrm{nM}$; $\mathrm{E}: \mathrm{T}$ ratio $=5: 1)$. Data are representative of at least two independent experiments, with similar results. ${ }^{\mathrm{a}} \mathrm{P}<0.05,{ }^{\mathrm{b}} \mathrm{P}<0.01,{ }^{\mathrm{c}} \mathrm{P} 0.001,{ }^{\mathrm{d}} \mathrm{P}<0.0001$.

were incubated at $37^{\circ} \mathrm{C}$ and then read on a microplate reader (model 3550; Bio-Rad Laboratories, Inc., Hercules, CA, USA) at a wavelength of $490 \mathrm{~nm}$. Growth inhibition of the target cells was calculated as follows: percentage growth inhibition of target cells $=[1-(\mathrm{A} 490$ of treatment - A490 of background $) /$ (A490 of control - A490 of background)] x 100 (30).

In vivo tumor models. Female 8-week-old severe combined immunodeficient (SCID) mice (Fox CHASE C.B.-17/Icr-Scid Jcr) (Clea Japan, Inc., Tokyo, Japan) were injected with $5 \times 10^{6}$ TFK-1 cells subcutaneously into the dorsal thoracic wall on day 0 . Using these mice, we evaluated three models of efficacy.

In the first model, we evaluated the antitumor activity of hEx3-Db and cetuximab. Ten days after TFK-1 injection, $\mathrm{hEx} 3-\mathrm{Db}(0.2,2$, or $20 \mu \mathrm{g})$ or cetuximab $(500 \mu \mathrm{g})$ were injected intravenously via the tail vein on 4 consecutive days (days 1,2, 3 and 4 ) with or without T-LAK cells $\left(2.0 \times 10^{7}\right)+$ IL-2 (250 IU). In the second model, we assessed the monotherapeutic effect of hEx3-Db alone. Ten days after the initial TFK-1 injection, hEx3-Db (2, 20 or $200 \mu \mathrm{g})$ or PBS were injected intravenously via the tail vein on 4 consecutive days (days 1,2,3 and 4). In the third model, we compared the antitumor activity of hEx3-Db with the IgG-like BsAbs. Ten days after the initial TFK-1 injection, hEx3-Db $(20 \mu \mathrm{g})$, hEx3-scDb-Fc $(20 \mu \mathrm{g})$, or hEx3$\mathrm{scFv}-\mathrm{Fc}(20 \mu \mathrm{g})$ were injected intravenously via the tail vein on 4 consecutive days (days 1,2, 3 and 4) with or without effector cells [T-LAK cells $\left(2.0 \times 10^{6}\right)$ or PBMCs $\left(4.0 \times 10^{6}\right)$ ] and IL-2 (250 IU). In this experiment we used 2.0x10 $10^{6}$ T-LAK cells to mimic physiological conditions.

Tumor size was measured with a caliper weekly for 10 weeks. When the tumors grew to approximately $5 \mathrm{~mm}$ in diameter, the mice were randomly divided. Animals whose tumors did not reach $5 \mathrm{~mm}$ in diameter were excluded from the experiments. The approximate tumor volume $(\mathrm{V}$, in cubic millimeters) was calculated from linear measurements of the width ( $\mathrm{A}$, in millimeters) and length ( $\mathrm{B}$, in millimeters) as follows: $\mathrm{V}=\left(\mathrm{A}^{2} \mathrm{x} \mathrm{B}\right) / 2$.

These animal experiments were reviewed by the Committee on Ethics in Animal Experiments of Tohoku University and were carried out under the Guidelines for Animal Experiments of Tohoku University and the Law and Notification of the Japanese Government.

Statistical analysis. Results from the growth inhibition assays in vitro were compared by the unpaired t-test. In the mouse models, the tumor growth inhibition in the control group was compared with that in each treatment group using an unpaired $\mathrm{t}$-test.

\section{Results}

In vitro growth inhibition for the various cancer cell lines. To compare the efficacy of the BsAbs (hEx3-Db, hEx3-scFv-Fc, and hEx3-scDb-Fc) with cetuximab, we performed growth inhibition assays for the various cancer cell lines. Expression levels of EGFR in each cell line estimated by flow cytometry are summarized in Table I. In comparison to cetuximab, which had little effect on the activity of T-LAK cells, hEx3-Db effectively inhibited the growth of several lines of cancer cells (Table I). The most intense effect on all tested cell lines was observed in the two IgG-like BsAbs, especially hEx3-scFv-Fc, which showed nearly $100 \%$ killing activity even for the cell line with the lowest EGFR expression levels, MCF-7.

In the presence of PBMCs, cetuximab inhibited the growth of several cancer cell lines by the induction of ADCC via the human Fc region (Table II). hEx3-Db without the Fc region showed growth inhibition for half of the cell lines. In this 
Table II. Percentage of growth inhibition of Ab with PBMCs vs. PBMCs alone in various cancer cell lines.

\begin{tabular}{lrcccc}
\hline Target cells & PBMC alone & Cetuximab & hEx3-Db & hEx3-scFv-Fc & hEx3-scDb-Fc \\
\hline TFK-1 & $3.8 \pm 4.1$ & $44.9 \pm 9.8^{\mathrm{b}}$ & $19.1 \pm 9.0^{\mathrm{b}}$ & $98.7 \pm 0.9^{\mathrm{c}}$ & $90.3 \pm 2.2^{\mathrm{c}}$ \\
HuCC-T1 & $-3.5 \pm 2.9$ & $-0.2 \pm 2.9^{\mathrm{a}}$ & $0.9 \pm 1.6^{\mathrm{b}}$ & $19.8 \pm 2.8^{\mathrm{c}}$ & $15.0 \pm 2.4^{\mathrm{c}}$ \\
OCUCh-LM1 & $3.2 \pm 4.0$ & $7.0 \pm 12.8$ & $6.3 \pm 12.6$ & $92.8 \pm 1.6^{\mathrm{c}}$ & $74.5 \pm 8.5^{\mathrm{c}}$ \\
A431 & $5.1 \pm 5.4$ & $9.9 \pm 12.6$ & $61.0 \pm 5.1^{\mathrm{c}}$ & $71.8 \pm 2.0^{\mathrm{c}}$ & $66.8 \pm 3.7^{\mathrm{c}}$ \\
Kato-III & $27.9 \pm 2.7$ & $32.0 \pm 6.3$ & $30.3 \pm 7.7$ & $97.5 \pm 1.9^{\mathrm{c}}$ & $100.1 \pm 0.3^{\mathrm{c}}$ \\
DLD-1 & $6.5 \pm 2.5$ & $22.6 \pm 3.4^{\mathrm{c}}$ & $34.3 \pm 4.6^{\mathrm{c}}$ & $96.7 \pm 0.5^{\mathrm{c}}$ & $93.8 \pm 1.6^{\mathrm{c}}$ \\
SW480 & $9.3 \pm 3.9$ & $8.4 \pm 7.1$ & $-0.9 \pm 8.8$ & $72.4 \pm 5.0^{\mathrm{c}}$ & $68.8 \pm 2.7^{\mathrm{c}}$ \\
SK-BR-3 & $-13.8 \pm 3.7$ & $46.7 \pm 4.8^{\mathrm{c}}$ & $55.6 \pm 7.1^{\mathrm{c}}$ & $89.6 \pm 2.1^{\mathrm{c}}$ & $90.0 \pm 0.8^{\mathrm{c}}$ \\
MCF-7 & $5.7 \pm 3.6$ & $12.3 \pm 9.9$ & $6.6 \pm 7.4$ & $95.9 \pm 0.9^{\mathrm{c}}$ & $97.5 \pm 0.9^{\mathrm{c}}$ \\
\hline
\end{tabular}

Percentage \pm SD of growth inhibition of bispecific antibodies or monospecific antibodies with PBMCs $(\mathrm{Ab}, 0.1 \mathrm{nM}, \mathrm{E}: \mathrm{T}$ ratio $=5: 1)$. Data are representative of at least two independent experiments, with similar results. ${ }^{\mathrm{a}} \mathrm{P}<0.05,{ }^{\mathrm{b}} \mathrm{P}<0.001,{ }^{\mathrm{c}} \mathrm{P}<0.0001$.

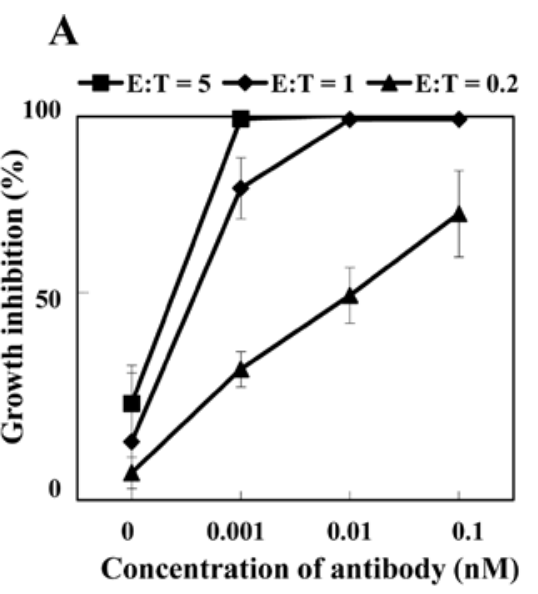

C

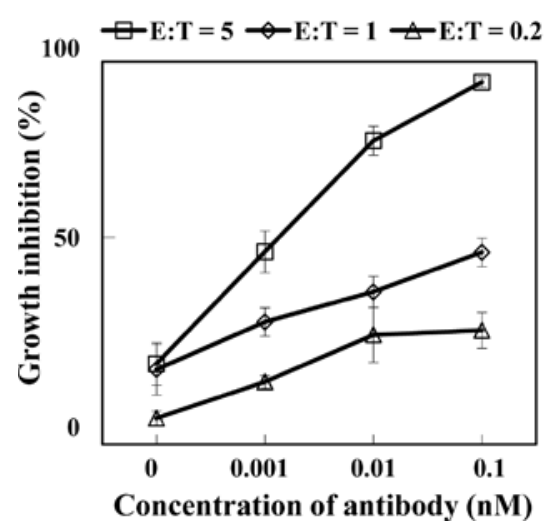

\section{B}

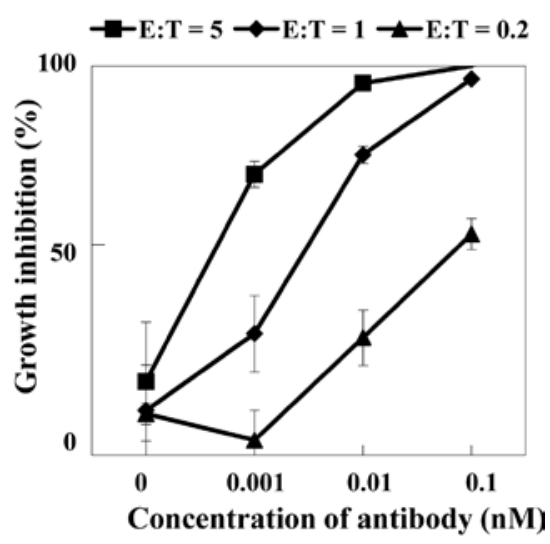

D

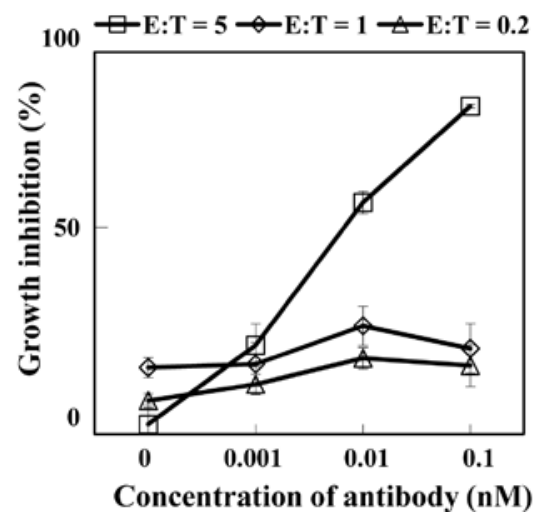

Figure 2. Percentage of growth inhibition was determined by a 48-h MTS assay. Concentrations of IgG-like BsAbs and E:T ratios of effector cells added to TFK-1 are displayed as follows: (A) hEx3-scFv-Fc + T-LAK cells; (B) hEx3-scDb-Fc + T-LAK cells; (C) hEx3-scFv-Fc + PBMCs; and (D) hEx3-scDb-Fc + PBMCs. Data are presented as the mean value \pm SD and are representative of at least three independent experiments with similar results.

case, a small fraction of CD3-positive cells in the PBMCs probably contributed to the cytotoxic effect. In contrast, significant growth inhibition for all cancer cell lines was observed in the IgG-like BsAbs, with no major differences between hEx3-scFv-Fc and hEx3-scDb-Fc $(\mathrm{P}<0.0001)$, which were unlike the results from using T-LAK cells as effector cells. Thus, the IgG-like BsAbs, with their intense crosslinking effects caused by bivalent binding to each antigen and secondary immune functions such as ADCC, are highly effective against a wide range of cancer cell lines.

For further comparison between hEx3-scFv-Fc and hEx3-scDb-Fc, we performed the growth inhibition assay at 


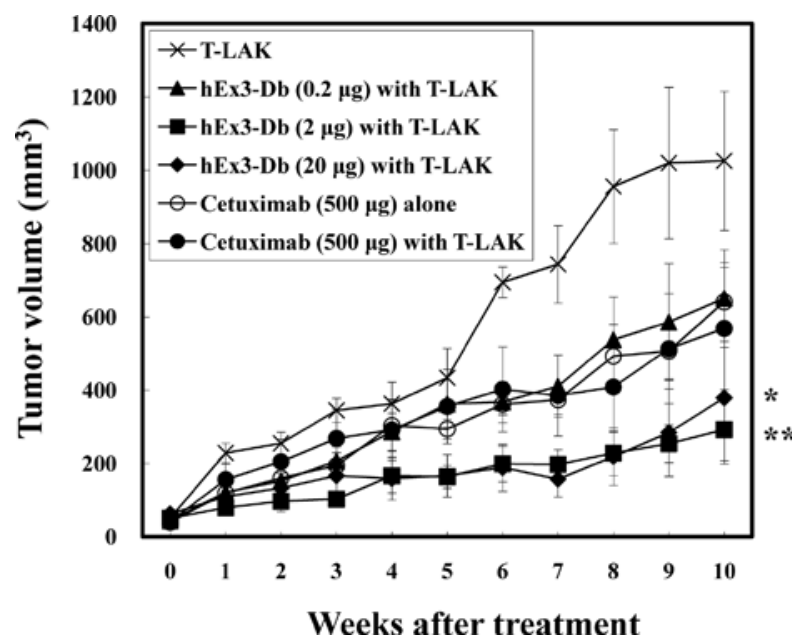

Figure 3. Treatment with hEx3-Db and cetuximab on xenografted TFK-1 tumors in SCID mice. The TFK-1 cells were injected subcutaneously into SCID mice 10 days before treatment. Then, hEx3-Db or cetuximab were injected intravenously via the tail vein on 4 consecutive days (days 1, 2, 3 and 4$)$ with or without T-LAK cells $\left(2.0 \times 10^{7}\right)+$ IL-2 (250 IU) as follows T-LAK cells + IL-2 (Xs); hEx3-Db $(0.2 \mu \mathrm{g})+$ T-LAK cells + IL-2 (closed triangles); hEx3-Db (2 $\mu \mathrm{g})+$ T-LAK cells + IL-2 (closed squares); hEx3-Db $(20 \mu \mathrm{g})+$ T-LAK cells + IL-2 (closed diamonds); cetuximab $(500 \mu \mathrm{g})$ alone (open circles); cetuximab $(500 \mu \mathrm{g})+$ T-LAK cells + IL-2 (closed circles). Points, median tumor volumes from each treatment group $(n=5$ mice/treatment group); bars, standard errors of the mean (SEM). ${ }^{*} \mathrm{P}<0.05,{ }^{* *} \mathrm{P}<0.01$, for each group vs. the control group (T-LAK cells alone).

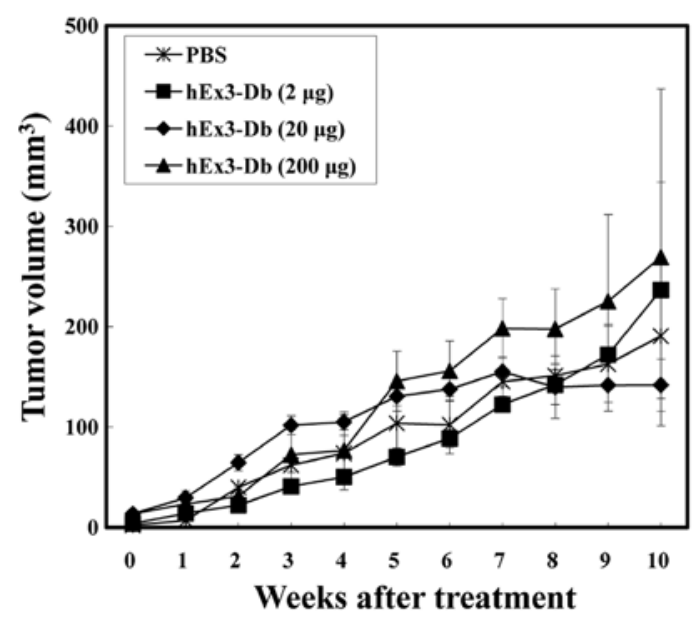

Figure 4. Treatment with hEx3-Db alone for xenografted TFK-1 tumors in SCID mice. The TFK-1 cells were injected subcutaneously into the mice 10 days before treatment. Then, hEx3-Db or PBS were injected intravenously via the tail vein on 4 consecutive days (days 1,2,3 and 4) as follows: PBS (Xs); hEx3-Db (2 $\mu \mathrm{g})$ (closed squares); hEx3-Db (20 $\mu \mathrm{g})$ (closed diamonds); hEx3-Db $(200 \mu \mathrm{g})$ (closed triangles). Points, median tumor volumes from each treatment group ( $\mathrm{n}=2-3$ mice/treatment group); bars, SEM.

concentrations from $0.001-0.1 \mathrm{nM}$ and at E:T ratios from 0.2 to 5 by using TFK-1 with T-LAK cells or PBMCs. In the presence of T-LAK cells, growth inhibition with hEx3$\mathrm{scFv}-\mathrm{Fc}$ was higher than that with $\mathrm{hEx} 3-\mathrm{scDb}-\mathrm{Fc}$, and was dose- and E:T ratio-dependent (Fig. 2A and B). In contrast, when PBMCs were used as the effector cells, the differences between the effects of the two IgG-like BsAbs were less than those in the presence of T-LAK cells, especially at high E:T ratios (Fig. $2 \mathrm{C}$ and $\mathrm{D}$ ). Thus, these results may suggest that the functional mechanism of IgG-like BsAbs differs by the kind of effector cell.

In vivo efficacy of hEx3-Db in tumor xenografted mice. To evaluate antitumor activity in vivo, hEx3-Db and cetuximab were injected for 4 consecutive days into SCID mice injected with TFK-1. Compared with the group injected with T-LAK cells alone, significant inhibition of tumor growth was observed in the groups co-injected with $\mathrm{hEx} 3-\mathrm{Db}(\mathrm{n}=5 ; 0.2 \mu \mathrm{g}$, $\mathrm{P}<0.05 ; 2 \mu \mathrm{g}, \mathrm{P}<0.01$ ) (Fig. 3). Even the 0.2- $\mu \mathrm{g}$ injection of $\mathrm{hEx} 3-\mathrm{Db}$ showed an effect comparable to the 500- $\mu \mathrm{g}$ injection of cetuximab. However, the effect of cetuximab was independent of the presence of T-LAK cells.

In vivo monotherapeutic effects of hEx3-Db in tumor xenografted mice. To evaluate the monotherapeutic effect of $\mathrm{hEx} 3-\mathrm{Db}$ alone, $\mathrm{hEx} 3-\mathrm{Db}$ was injected at different concentrations into 2 or 3 SCID mice per treatment group (inoculated with TFK-1). No inhibitory effects were found at any hEx3-Db concentration (2-200 $\mu \mathrm{g}$, Fig. 4). hEx3-Db did not induce EGFR-mediated growth inhibition or ADCC. Therefore, effector cells with CD3-positive phenotypes are essential for $\mathrm{hEx} 3-\mathrm{Db}$ to induce any antitumor effects.

In vivo efficacy of IgG-like BsAbs in tumor xenografted mice. To compare the antitumor activity of hEx3-Db with IgG-like BsAbs, each BsAb was injected into the xenografted mice $(n=7$ or 8$)$ with or without effector cells for 4 consecutive days. The growth inhibitory effect of hEx3-Db was comparable to that of hEx3-scDb-Fc $(\mathrm{P}<0.05)$ independent of the kind of effector cell (Fig. 5A). Interestingly, the inhibitory effect on tumor growth by both of the IgG-like BsAbs was significant even in the absence of effector cells $(\mathrm{P}<0.05)$ (Fig. 5B and C). Similar to the cetuximab results, ADCC induced via the fused Fc portion and the inhibitory effect of EGFR-mediated growth signaling probably contributed to these monotherapeutic effects. However, no major differences in the effects of the two IgG-like BsAbs were observed, similar to the results from the in vitro experiment using PBMCs as effector cells, and the co-injection of T-LAK cells did not induce a remarkable additive effect in $\mathrm{hEx} 3-\mathrm{scDb}-\mathrm{Fc}$ and $\mathrm{hEx} 3-\mathrm{scFv}-\mathrm{Fc}$.

\section{Discussion}

IgG-like BsAbs, recombinant BsAbs containing a human Fc region, are attractive and realistically producible antibody forms. These forms have high therapeutic potency in recruiting cytotoxic $\mathrm{T}$ cells against tumor cells and inducing ADCC, and their greater molecular weight results in longer clearance half-lives than with the small BsAb Dbs $(22,31)$. In addition, the fusion of the $\mathrm{Fc}$ region enables convenient purification with protein $A(22,31-33)$.

Among the hEx3 BsAbs and cetuximab, hEx3-scFv-Fc showed the highest cytotoxicity in vitro to many kinds of cancer cell lines in the presence of T-LAK cells (Table I, Fig. 2). In some cases, the construction of recombinant antibodies with IgG-like BsAb causes steric hindrance that decreases affinity for each antigen and impedes bispecific binding (22). These results suggest a structural superiority of $\mathrm{hEx} 3-\mathrm{scFv}-\mathrm{Fc}$ to 


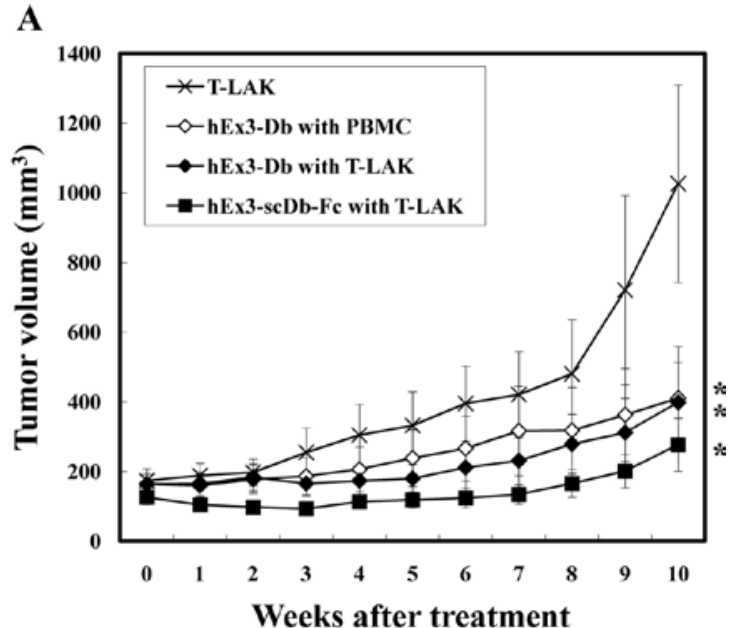

B

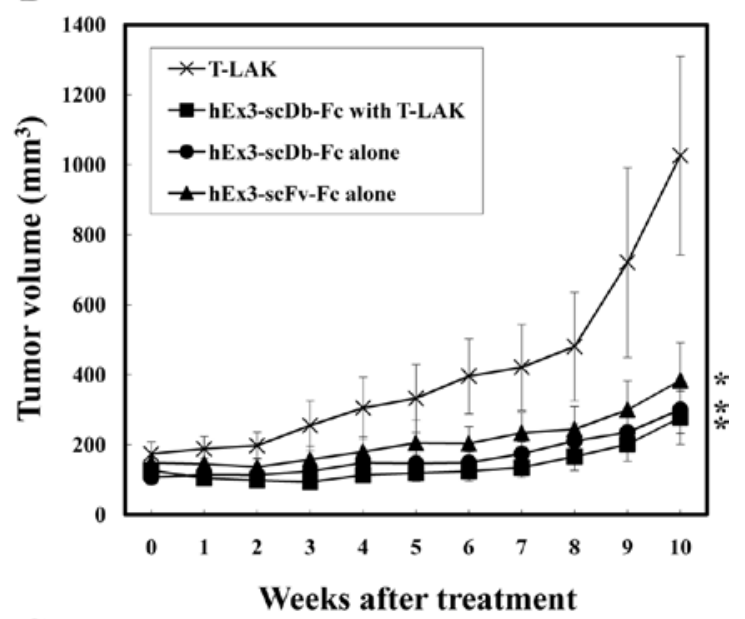

C

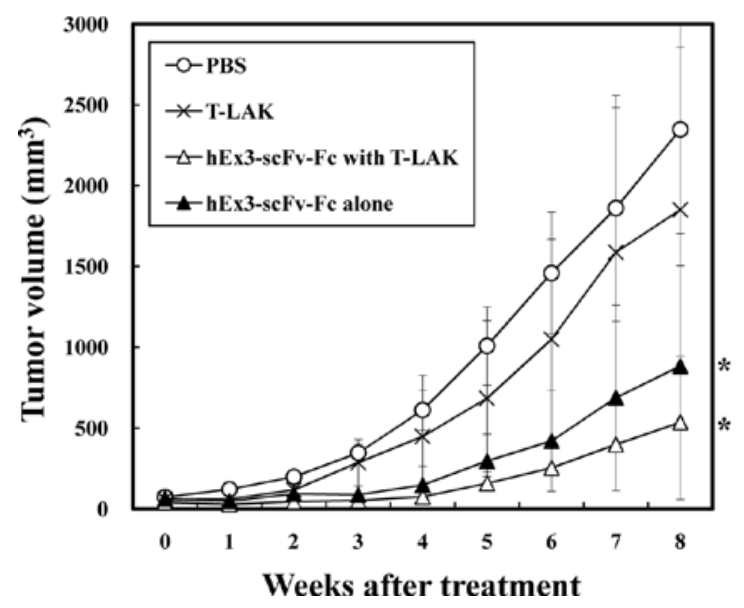

Figure 5. hEx3 BsAbs inhibit growth of TFK-1 xenografts. The TFK-1 cells $\left(5.0 \times 10^{6}\right)$ were injected subcutaneously into SCID mice 10 days before treatment. Then, hEx3-Db, hEx3-scDb-Fc, and hEx3-scFv-Fc were injected intravenously via the tail vein on 4 consecutive days (days 1,2,3 and 4) with or without effector cells [T-LAK cells $\left(2.0 \times 10^{6}\right)$ or PBMCs $\left.\left(4.0 \times 10^{6}\right)\right]+$ IL-2 (250 IU). (A) T-LAK cells + IL-2 (Xs; n=7); hEx3-Db $(20 \mu \mathrm{g})+$ PBMCs + IL-2 (open diamonds; $\mathrm{n}=7)$; hEx3-Db $(20 \mu \mathrm{g})+\mathrm{T}-\mathrm{LAK}$ cells + IL-2 (closed diamonds; $\mathrm{n}=7)$; hEx3-scDb-Fc $(20 \mu \mathrm{g})+\mathrm{T}-\mathrm{LAK}$ cells + IL-2 (closed squares; n=7). (B) T-LAK cells + IL-2 (Xs; n=7); hEx3-scDb-Fc $(20 \mu \mathrm{g})+$ T-LAK cells + IL-2 (closed squares; $\mathrm{n}=7)$; hEx3-scDb-Fc $(20 \mu \mathrm{g})$ (closed circles; $\mathrm{n}=8)$; hEx3-scFv-Fc $(20 \mu \mathrm{g})$ (closed triangles; $\mathrm{n}=8)$. (C) PBS (open circles; $\mathrm{n}=5)$; T-LAK cells + IL-2 (Xs; $\mathrm{n}=5)$; hEx3-scFv-Fc $(20 \mu \mathrm{g})+$ T-LAK cells + IL-2 (open triangles; $\mathrm{n}=5)$; hEx3-scFv-Fc $(20 \mu \mathrm{g})$ (closed triangles; $\mathrm{n}=5$ ). Points, median tumor volumes from each treatment group; bars, SEM. ${ }^{*} \mathrm{P}<0.05$, for each group vs. T-LAK cells alone or PBS (only for hEx3$\mathrm{scFv}-\mathrm{Fc}$ alone in $\mathrm{C}$ ).
$\mathrm{hEx} 3-\mathrm{scDb}-\mathrm{Fc}$ in the cross-linkage of effector cells to tumor cells.

Both in vitro and in vivo, the results indicated that CD3-positive effector cells are essential for the induction of potent antitumor effects of hEx3-Db without Fc (Table I, Figs. 3 and 4). In contrast, cetuximab and both IgG-like BsAbs showed monotherapeutic effects in the in vivo therapeutic models (Figs. 3 and 5B and C). Immune-deficient mice xenografted with human cancer can be used to evaluate ADCC induced from human IgG1 antibodies (34) and glycosylation in the $\mathrm{Fc}$ region of the antibody-heavy chain is indispensable for both their interactions with $\mathrm{Fc}$ receptors and $\mathrm{FcR}$-mediated effector functions, including ADCC $(35,36)$. We previously confirmed that the glycosylation pattern of $\mathrm{hEx} 3-\mathrm{scDb}-\mathrm{Fc}$ is quite similar to that of humanized IgG1 produced by $\mathrm{CHO}$ cells (37) and the binding of hEx3-scFv-Fc mediates the inhibition of the phosphorylation of protein kinase (23). These facts suggest that the monotherapeutic effects of IgG-like BsAbs based on hEx3 are due to the induction of ADCC and the inhibition of receptor tyrosine kinase, similar to the mechanisms that have been demonstrated for cetuximab $(38,39)$.

In contrast, remarkable differences were not observed between $\mathrm{hEx} 3-\mathrm{scFv}-\mathrm{Fc}$ and $\mathrm{hEx} 3-\mathrm{scDb}-\mathrm{Fc}$ in vitro (Table II, Fig. $2 \mathrm{C}$ and $\mathrm{D}$ ) or in vivo (Fig. $5 \mathrm{~B}$ ) if the functional mechanism of the recombinant $\mathrm{Ab}$ was ADCC. Furthermore, co-injection of T-LAK cells did not induce a remarkable additive effect in either IgG-like BsAb in vivo (Fig. 5B and C). These results may indicate that due to the steric hindrance on binding to CD3- and Fc-receptor-positive phenotypes, the IgG-like BsAbs based on hEx3 can not both direct $\mathrm{T}$ lymphocytes to tumor cells and efficiently induce ADCC. Although further studies of animal models are necessary to confirm ADCC dependence using Fc-receptor-deficient mice and to compare in detail IgG-like BsAbs with cetuximab, our results suggest the potential of a design that can efficiently direct effector cells toward tumor cells with the induction of secondary immune functioning for the development of even more effective IgG-like BsAbs.

In conclusion, although $\mathrm{hEx} 3$-scFv-Fc showed the highest cytotoxicity in vitro, the high molecular weight of the scFv-IgG format $(200 \mathrm{kDa})$ makes it hard to prepare sufficient amounts of recombinant antibodies for further study (22). With monotherapeutic effects comparable to $\mathrm{hEx} 3-\mathrm{scFv}-\mathrm{Fc}$ in vivo, $\mathrm{hEx} 3-\mathrm{scDb}-\mathrm{Fc}$ may prove to be an attractive recombinant therapeutic antibody and become a more potent reagent by further modification (by exchanging domain order, redesigning the manner of fusion between the $\mathrm{Db}$ and the $\mathrm{Fc}$ portion, and introducing the mutation to minimize the steric hindrance). The production of a highly effective recombinant antibody would lead to a reduction in therapeutic dose, and thus, decrease medical costs in clinical settings.

\section{Acknowledgements}

This study was supported by Grants-in-Aid for Scientific Research from the Ministry of Education, Science, Sports, and Culture of Japan (R.A. and I.K.) and by grants from the New Energy and Industrial Technology Development Organization (NEDO) of Japan. Additional support was provided through the Program for Promotion of Fundamental Studies in Health Sciences of the National Institute of Biomedical Innovation. 


\section{References}

1. Fischer-Colbrie J, Witt A, Heinzl H, et al: EGFR and steroid receptors in ovarian carcinoma: comparison with prognostic parameters and outcome of patients. Anticancer Res 17: 613-619, 1997.

2. Nonomura A, Ohta G, Nakanuma Y, et al: Simultaneous detection of epidermal growth factor receptor (EGF-R), epidermal growth factor (EGF) and ras p21 in cholangiocarcinoma by an immunocytochemical method. Liver 8: 157-166, 1988.

3. Salomon DS, Brandt R, Ciardiello F and Normanno N: Epidermal growth factor-related peptides and their receptors in human malignancies. Crit Rev Oncol Hematol 19: 183-232, 1995.

4. Tosi E, Valota O, Negri DR, et al: Anti-tumor efficacy of an anti-epidermal-growth-factor-receptor monoclonal antibody and its $\mathrm{F}\left(\mathrm{ab}^{\prime}\right) 2$ fragment against high- and low-EGFR-expressing carcinomas in nude mice. Int J Cancer 62: 643-650, 1995.

5. Jung G, Brandl M, Eisner W, et al: Local immunotherapy of glioma patients with a combination of 2 bispecific antibody fragments and resting autologous lymphocytes: evidence for in situ t-cell activation and therapeutic efficacy. Int J Cancer 91: 225-230, 2001.

6. Pfosser A, Brandl M, Salih H, Grosse-Hovest L and Jung G: Role of target antigen in bispecific-antibody-mediated killing of human glioblastoma cells: a pre-clinical study. Int J Cancer 80 : 612-616, 1999.

7. Reusch U, Sundaram M, Davol PA, et al: Anti-CD3 x antiepidermal growth factor receptor (EGFR) bispecific antibody redirects T-cell cytolytic activity to EGFR-positive cancers in vitro and in an animal model. Clin Cancer Res 12: 183-190, 2006.

8. Cao Y and Lam L: Bispecific antibody conjugates in therapeutics. Adv Drug Deliv Rev 55: 171-197, 2003.

9. Kufer P, Lutterbuse R and Baeuerle PA: A revival of bispecific antibodies. Trends Biotechnol 22: 238-244, 2004.

10. Arndt MA, Krauss J, Kipriyanov SM, Pfreundschuh M and Little M: A bispecific diabody that mediates natural killer cell cytotoxicity against xenotransplantated human Hodgkin's tumors. Blood 94: 2562-2568, 1999.

11. Alt M, Muller R and Kontermann RE: Novel tetravalent and bispecific IgG-like antibody molecules combining single-chain diabodies with the immunoglobulin gamma1 $\mathrm{Fc}$ or $\mathrm{CH} 3$ region. FEBS Lett 454: 90-94, 1999.

12. Schlereth B, Fichtner I, Lorenczewski G, et al: Eradication of tumors from a human colon cancer cell line and from ovarian cancer metastases in immunodeficient mice by a single-chain Ep-CAM-/CD3-bispecific antibody construct. Cancer Res 65: 2882-2889, 2005.

13. Wu AM, Chen W, Raubitschek A, et al: Tumor localization of anti-CEA single-chain Fvs: improved targeting by non-covalent dimers. Immunotechnology 2: 21-36, 1996.

14. Cochlovius B, Kipriyanov SM, Stassar MJ, et al: Treatment of human B cell lymphoma xenografts with a CD3 x CD19 diabody and T cells. J Immunol 165: 888-895, 2000.

15. Asano R, Sone Y, Makabe K, et al: Humanization of the bispecific epidermal growth factor receptor x CD3 diabody and its efficacy as a potential clinical reagent. Clin Cancer Res 12: 4036-4042, 2006

16. Asano R, Ikoma K, Sone Y, et al: Highly enhanced cytotoxicity of a dimeric bispecific diabody, the hEx3 tetrabody. J Biol Chem 285: 20844-20849, 2010.

17. Park SS, Ryu CJ, Kang YJ, Kashmiri SV and Hong HJ: Generation and characterization of a novel tetravalent bispecific antibody that binds to hepatitis B virus surface antigens. Mol Immunol 37: 1123-1130, 2000.

18. Shen J, Vil MD, Jimenez X, et al: Single variable domain antibody as a versatile building block for the construction of IgG-like bispecific antibodies. J Immunol Methods 318: 65-74, 2007.
19. Lu D, Zhang H, Ludwig D, et al: Simultaneous blockade of both the epidermal growth factor receptor and the insulin-like growth factor receptor signaling pathways in cancer cells with a fully human recombinant bispecific antibody. J Biol Chem 279: 2856-2865, 2004.

20. Carter P: Bispecific human IgG by design. J Immunol Methods 248: 7-15, 2001.

21. Lu D, Jimenez X, Zhang H, et al: Di-diabody: a novel tetravalent bispecific antibody molecule by design. J Immunol Methods 279: 219-232, 2003.

22. Marvin JS and Zhu Z: Recombinant approaches to IgG-like bispecific antibodies. Acta Pharmacol Sin 26: 649-658, 2005.

23. Asano R, Watanabe Y, Kawaguchi H, et al: Highly effective recombinant format of a humanized IgG-like bispecific antibody for cancer immunotherapy with retargeting of lymphocytes to tumor cells. J Biol Chem 282: 27659-27665, 2007.

24. Asano R, Kawaguchi H, Watanabe Y, et al: Diabody-based recombinant formats of humanized IgG-like bispecific antibody with effective retargeting of lymphocytes to tumor cells. J Immunother 31: 752-761, 2008.

25. Asano R, Sone Y, Ikoma K, et al: Preferential heterodimerization of a bispecific diabody based on a humanized anti-EGFR antibody 528. Protein Engin Des Sel 21: 597-603, 2008.

26. Yamada N, Chung YS, Arimoto Y, Sawada T, Seki S and Sowa M: Establishment of a new human extrahepatic bile duct carcinoma cell line (OCUCh-LM1) and experimental liver metastatic model. Br J Cancer 71: 543-548, 1995.

27. Saijyo S, Kudo T, Suzuki M, et al: Establishment of a new extrahepatic bile duct carcinoma cell line, TFK-1. Tohoku J Exp Med 177: 61-71, 1995.

28. Asano R, Ikoma K, Kawaguchi H, et al: Application of the $\mathrm{Fc}$ fusion format to generate tag-free bi-specific diabodies. FEBS J 277: 477-487, 2009.

29. Katayose Y, Kudo T, Suzuki M, et al: MUC1-specific targeting immunotherapy with bispecific antibodies: inhibition of xenografted human bile duct carcinoma growth. Cancer Res 56: 4205-4212, 1996.

30. Asano R, Ikoma K, Shimomura I, et al: Cytotoxic enhancement of a bispecific diabody by format conversion to tandem singlechain variable fragment (taFv): the case of the hEx3 diabody. J Biol Chem 286: 1812-1818, 2011.

31. Merchant AM, Zhu Z, Yuan JQ, et al: An efficient route to human bispecific IgG. Nat Biotechnol 16: 677-681, 1998.

32. Ridgway JB, Presta LG and Carter P: 'Knobs-into-holes' engineering of antibody $\mathrm{CH} 3$ domains for heavy chain heterodimerization. Protein Eng 9: 617-621, 1996.

33. Xie Z, Guo N, Yu M, Hu M and Shen B: A new format of bispecific antibody: highly efficient heterodimerization, expression and tumor cell lysis. J Immunol Methods 296: 95-101, 2005.

34. Clynes RA, Towers TL, Presta LG and Ravetch JV: Inhibitory Fc receptors modulate in vivo cytoxicity against tumor targets. Nat Med 6: 443-446, 2000.

35. Dwek RA: Glycobiology: more functions for oligosaccharides. Science 269: 1234-1235, 1995.

36. Jefferis R: Glycosylation as a strategy to improve antibody-based therapeutics. Nat Rev Drug Discov 8: 226-234, 2009.

37. Kim WD, Tokunaga M, Ozaki H, et al: Glycosylation pattern of humanized IgG-like bispecific antibody produced by recombinant CHO cells. Appl Microbiol Biotechnol 85: 535-542, 2010.

38. Fan Z, Lu Y, Wu X and Mendelsohn J: Antibody-induced epidermal growth factor receptor dimerization mediates inhibition of autocrine proliferation of A431 squamous carcinoma cells. J Biol Chem 269: 27595-27602, 1994

39. Kawaguchi Y, Kono K, Mimura K, Sugai H, Akaike H and Fujii H: Cetuximab induce antibody-dependent cellular cytotoxicity against EGFR-expressing esophageal squamous cell carcinoma. Int J Cancer 120: 781-787, 2007. 